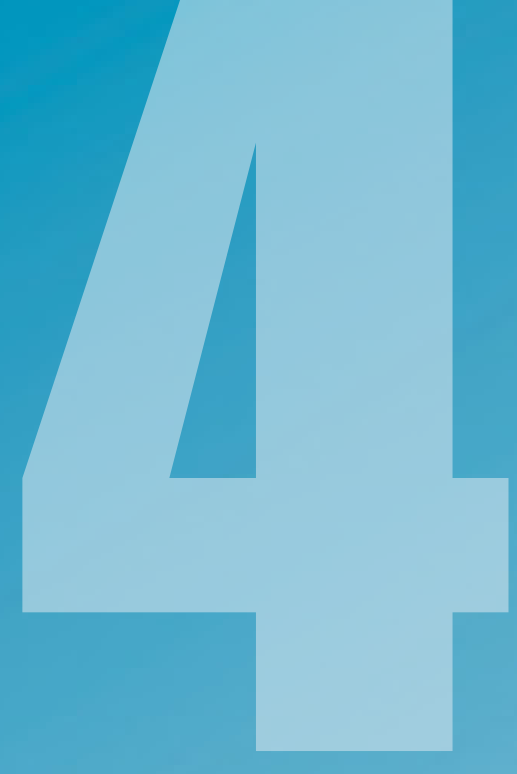

ÁMBITOS

REVISTA

INTERNACIONAL

DE COMUNICACIÓN

$N^{\circ} 46$

EDICIÓN OTOÑO

2019

ISSN: 1139-1979

E-ISSN: 1988-5733

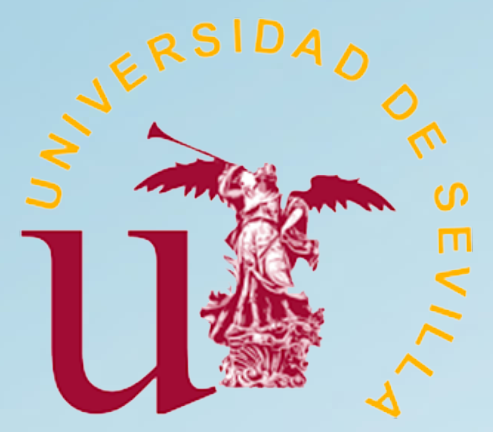




\section{ÍNDICE}

MONOGRAFICOS MONOGRAPHS

Presentación Monográfico. Comunicación emergente. Experiencias para el cambio social

Dra. Nereida López Vidales

Los formatos de televisión más consumidos por los jóvenes: telerrealidad y empoderamiento de la audiencia

Most consumed televisión formats by young people: real TV and the empowerment of the audience Nereida López Vidales, Leire Gómez Rubio, Elena Medina de la Viña

Nuevas herramientas, viejas costumbres El Contenido Generado por los Usuarios sobre el cambio climático en YouTube

New tools, old habits User Generated Content about climate change on YouTube

David Vicente Torrico

Tratamiento periodístico de personas LGTBIQ+ refugiadas: estudio de caso sobre Pride Barcelona 2018

Journalistic treatment of LGTBIQ+ refugees: case study on Pride Barcelona 2018

Hadriel Theodoro, Amparo Huertas Bailén

Tiempo Muerto, estudio de caso de un proyecto transmediático para la consecución de competencias universitarias

Tiempo Muerto, case study of a transmediatic project for the achievement of university competences Jose L. Carreño Villada, Miguel Ángel Díaz Monsalvo

Los universitarios millennials: uso de redes sociales y relación con las marcas

University Millennials: use of social media and engage with brands

Pedro Pablo Marín Dueñas, Esther Simancas González

Ali Ferzat: De la caricatura comunicativa en papel a la caricatura activista en los medios digitales

Ali Ferzat: From political cartoons in papers to political cartoons in digital media

Salud Adelaida Flores Borjabad

Direito à informação e literacia midiática: Reflexões sobre a questão do acesso

Right to information and media literacy: Reflections on the question of acce

Christiane Delmondes Versuti 
Eficacia de los influencers como recurso publicitario en la estrategia de los anunciantes locales Efficacy of influencers as an advertising resource in the strategy of local advertisers

Isabel Iniesta-Alemán

As redes sociais como ferramenta de marketing em instituições de ensino superior no Brasil Social networks as a marketing tool in higher education institutions in Brazil

Alcino Ricoy JR, Rogério Eduardo Rodrigues Bazi

Estudio sobre la conceptualización y el tratamiento informativo de la violencia de género en la prensa digital cubana

Study about the conceptualization and information treatment of gender violence in the Cuban digital press

Regla Ismaray Cabreja Piedra, Karina Escalona Peña

\section{ARTÍCULOS ARTICLES}

Uso de Twitter durante los debates electorales televisados en los comicios andaluces de 2018 The use of Twitter during the televised electoral debates in the 2018 Andalusian elections Julia Fontenla Pedreira, Erika Conde Vázquez, Carmen Máiz Bar

Quem averigua as notícias, os algoritmos ou jornalistas? A lógica crítica de C. S.

Peirce como processo de identificação de uma Fake News

Who checks the news, algorithms or journalists? The critical logic of C. S. Peirce as a

process for identifying a Fake News

Adelino de Castro Oliveira Simões Gala, Vania Baldi, Universidad de Aveiro

\section{RESEÑAS REVIEWS}

Nuevo ecosistema comunicativo digital: El consumidor

Juan Carlos Figuereo Benítez

Corpus toponímic de Beniarrés

Bianca Sánchez-Gutiérrez

The Future Computed. La inteligencia artificial y su papel en la sociedad y Pulsa actualizar. La aventura de redescubrir el alma de Microsoft y concebir un futuro mejor para todos 


\title{
Tratamiento periodístico de personas LGTBIQ+ refugiadas: estudio de caso sobre Pride Barcelona 2018
}

\author{
Journalistic treatment of LGTBIQ+ refugees: case study on Pride
} Barcelona 2018

Hadriel Theodoro, Escola Superior de Propaganda e Marketing de São Paulo (PPGCOM-ESPM), Universitat Autònoma de Barcelona, ESPM - Campus Álvaro Alvim | Secretaria do PPGCOM

Rua Dr. Álvaro Alvim, 123 - Vila Mariana - São Paulo / SP / Brasil - CEP 04018-010 hgtheodoro@gmail.com | Orcid: https://orcid.org/0000-0001-8491-4544

Amparo Huertas Bailén, Universitat Autònoma de Barcelona

Campus UAB - Edificio N, planta 1 - 08193

Bellaterra (Cerdanyola del Vallès) - Barcelona (España)

amparo.huertas@uab.cat | Orcid: https://orcid.org/0000-0002-8851-5417

DOI: http://dx.doi.org/10.12795/Ambitos.2019.i46.04

\begin{abstract}
Resumen
El objetivo central de este trabajo es investigar el tratamiento periodístico de las personas LGTBIQ+ refugiadas. Partimos de una reflexión teórica sobre las cuestiones de la representación mediática y la (in)visibilidad de la migración de sujetos LGTBIQ+. En seguida, hemos analizado un corpus formado por 17 noticias sobre la Pride Barcelona 2018, cuyo lema fue: "Por los refugiados LGTBI". Todos ellos son textos publicados en tres periódicos españoles en su edición online (El País, El Mundo y La Vanguardia). Este estudio de caso se realiza con mirada cualitativa. En términos generales, los resultados apuntan hacia una ausencia de temas de discusión básicos
\end{abstract}


para entender la situación de las personas LGTBIQ+ refugiadas. A pesar del lema del evento abordado por las noticias analizadas, la temática queda silenciada y la presencia del colectivo LGTBIQ+ es mínima.

\section{Abstract}

The main objective of this work is to investigate the journalistic treatment of LGTBIQ+ refugees. We start with a theoretical reflection on the issue of media representations and the (in) visibility of the migration of $L G T B I Q+$ subjects. Then, we have analyzed a corpus consisting of 17 news about the Pride Barcelona 2018, whose motto was: "For the LGTBI refugees". All of them are texts published in three Spanish newspapers in their online edition (El País, El Mundo and La Vanguardia). This case study is carried out qualitatively. In general terms, the results point to an absence of basic discussion topics to understand the situation of $L G T B I Q+$ refugees. Despite the motto of the event addressed by the news analyzed, the theme is silenced and the presence of the $L G T B I Q+$ collective is minimal.

Palabras clave: Tratamiento periodístico, Refugio, Sujetos LGTBIQ+, Pride BCN 2018.

Keywords: Journalistic treatment, Refuge, Subjects LGTBIQ+, Pride BCN 2018.

\section{INTRODUCCIÓN}

Las migraciones son un fenómeno social complejo y multifactorial, y su comprensión engloba diversas variables (Mezzadra, 2005). Una de ellas son las identidades de género y las orientaciones sexuales, aunque este asunto haya sido prácticamente ignorado. Prueba de ello es que hasta los años 1980 los estudios migratorios no atendieron a la participación de las mujeres en los desplazamientos humanos - situación que va a cambiar principalmente gracias a las contribuciones teóricas y epistemológicas del feminismo (Krzeslo, 2007; Gregorio, 1998; Femenías, 2007).

Ahora bien, lo que sí es cierto es que, cuando tratamos sobre las migraciones de sujetos LGTBIQ+ (lesbianas, gays, travestis, transgéneros, transexuales, bisexuales, intersexo, queer y otras minorías derivadas del nexo sexo-género-sexualidad), las capas de invisibilidad son aún mayores (Wesling, 2008). Y esto no es una característica exclusiva del ámbito académico, sino que es de carácter general. Aparece en todas las áreas, institucional, política, jurídica e, incluso, mediática. Esta invisibilidad es resultado de la hegemonía institucionalizada de la heterosexualidad y de la cisgeneridad ${ }^{1}$, que ha conseguido acabar ocultando la representación de las diferencias en el espacio público. Las minorías, nos recuerda Huertas (2018, p. 44), "son grupos oprimidos (quienes ostentan el poder abusan de ellos), 'sin voz' o 'mudos' (otros hablan por ellos) y 'sin agencia' (otros deciden por ellos)". 
Pero la cuestión importante aquí no es sólo la necesidad de visibilizar, sino también cómo mostrar esas realidades, pues una mera reproducción de prejuicios y estereotipos no haría otra cosa que agravar la condición de precariedad o estigmatización (Butler, 2011). Es evidente que esto supone un gran esfuerzo para la práctica periodística. Krzeslo (2007) habla de una "corrección de la mirada" y destaca la necesidad de recoger las especificidades y singularidades de las experiencias migratorias de esos sujetos en las narrativas sobre la temática.

En lo que se refiere a la esfera mediática de forma específica, se debe reflexionar también sobre el papel de los medios de comunicación en las experiencias de quienes migran. Los medios, en su dimensión sociocultural, forman parte inexorablemente de la construcción de la vida cotidiana (Silverstone, 2010). De hecho, son esenciales en la arquitectura de espacios estratégicos de interacción. Téngase en cuenta que, en ellos, aparecen funciones tan fundamentales en la construcción de la ciudadanía como son la producción y el mantenimiento de vínculos de sociabilidad (locales o transnacionales), la construcción de una opinión pública o la creación de imaginarios específicos sobre los lugares de origen y de destino y también del propio sujeto migrante. Los contenidos mediáticos, en consecuencia, acaban afectando los desplazamientos y la adaptación al nuevo contexto sociocultural en el que se encuentra el sujeto migrante. Piénsese, por ejemplo, en el modo en que los medios abordan el islam y su influencia en la vida de las personas migrantes que visibilizan su creencia religiosa (Huertas y Luna, 2017).

Teniendo en cuenta todo lo expuesto hasta aquí, nos planteamos indagar sobre la representación mediática de las personas refugiadas $L G T B I Q+{ }^{2} Y$ lo hacemos a partir del análisis del tratamiento que la prensa española dio a la Pride Barcelona $2018^{3}$, cuyo lema fue "Por los refugiados LGTBI". Nuestro objeto de estudio puede expresarse a partir de esta idea: si los medios de comunicación no suelen visibilizar la inmigración de personas LGTBIQ+, ¿de qué modo la presentan cuando deciden abordarla?

En primer lugar, realizamos una reflexión teórica sobre la (de)construcción de las representaciones mediáticas y sobre cómo estas están vinculadas a la formación de la esfera pública, íntimamente dependiente, a su vez, de la capacidad de participación política de los sujetos. También abordamos la cuestión de los regímenes de (in)visibilidad de los sujetos migrantes LGTBIQ+, destacando la siguiente paradoja: por un lado, su visibilización en la esfera pública (donde está el dominio mediático) les sirve para poder legitimar las luchas por su reconocimiento y derechos como ciudadanía; por otro, esa misma visibilización puede serles perjudicial, dadas las normatizaciones hegemónicas sobre las identidades de género y orientaciones sexuales. A continuación, exponemos los resultados de nuestro estudio de campo. Tras una búsqueda de noticias publicadas sobre la Pride BCN 2018 por tres diarios españoles en su edición online, El País, El Mundo y La Vanguardia, se hallaron 17 textos. El material analizado fue publicado entre mayo y julio de 2018 , es decir, en un periodo temporal que comprende 
desde el mes anterior a la celebración de la Pride BCN 2018 hasta el mes posterior. Nuestro análisis es de carácter cualitativo.

\section{REPRESENTACIÓN MEDIÁTICA: DE LA VISUALIDAD A LA VISIBILIDAD}

El concepto de representación mediática está fuertemente relacionado con el de visibilidad, y, además, ambos están estrechamente vinculados al ámbito de la esfera pública. Para Hanna Arendt (2007), la esfera pública se construye a partir de las relaciones sociales establecidas entre los sujetos en un determinado espacio. Por esa razón, la esfera pública depende de la posibilidad de que haya un real "hacer político", que, según Arendt (2007), debería basarse en la pluralidad y en las diferencias. Sin embargo, las innumerables relaciones de poder (de orden cultural, económico, educativo, lingüístico, religioso, etc.) generan jerarquías en lo que se refiere tanto a la posibilidad de integración y participación en la esfera pública como en el propio ejercicio de ciudadanía. Estas jerarquías determinan quienes son merecedores de opresión y quienes, de privilegios.

En el mundo contemporáneo, estas visibilidades están profundamente asociadas a los medios de comunicación y a los avances tecnológicos que se dan en este terreno. No cabe duda de la centralidad que hoy tienen las mediaciones en la vida cotidiana (Silverstone, 2010). Pero, al mismo tiempo, no podemos olvidar que los medios no están exentos de principios (ideológicos, económicos, políticos, etc.) que marcan sus intereses. En consecuencia, las visibilidades generadas y difundidas por los medios no pueden considerarse como algo neutro, sino que responden a unos objetivos. Los medios recogen unas fuentes de información y anulan otras, optan por un enfoque y descartan otros, seleccionan unas declaraciones y rechazan otras. Es decir, hablar de visibilidad conlleva también pensar en la invisibilidad (Charaudeau, 2009).

Para las minorías sociales, como es el caso de los sujetos migrantes $L G T B I Q+$, la visibilidad en la esfera pública es esencial como herramienta para promover la necesidad de una política de la diferencia, que no sólo reconozca su existencia sino también las necesidades específicas de sus vidas. Obviamente no se trata de un proceso simple, pues estamos hablando de una visibilidad inclusiva, que huya de los estereotipos y prejuicios derivados de la imposición de lo heterocisnormativo. Además, otros espacios institucionales e instancias, como la escuela, la familia, el sistema sanitario, el Estado, la Iglesia, etc., también pueden generar discursos y prácticas discriminatorias en lo que concierne a las diferentes expresiones de género y/u orientaciones sociales, provocando la necesidad de mantener luchas políticas de resistencia y de (re)existencia por parte de los sujetos LGTBIQ+. Cuanto más represivo es el contexto sociocultural en el que el medio está inmerso, mayores son los riesgos de silenciamiento y más posibilidades tienen las valoraciones morales sobre los géneros y orientaciones sexuales no normativos de estar presentes. 
Así, al pensar sobre cómo se producen esas imágenes, cómo son vehiculadas y qué tipo de recepción predisponen, resulta interesante recordar a Hall (2013) y su noción sobre las "trampas de la visibilidad", expresión que le permite reflexionar sobre las representaciones estereotipadas. Hall (2013) nos ayuda a concluir que la mera visibilidad mediática de las diferencias no es suficiente para extinguir las desigualdades. Pero, en cualquier caso, para las minorías, la presencia mediática es fundamental para su "hacer político", ya que esta puede contribuir a alterar los contextos socioculturales que se sostienen sobre la desigualdad social.

Una vez entendido que las tecnologías de la información y la comunicación (TICs) son esenciales para el desarrollo del espacio público y, consecuentemente, para el ejercicio de ciudadanía (Silverstone, 2010), las visibilidades y representaciones mediáticas de la diferencia van ganando presencia. Aunque las TICs - sobre todo Internet - estén reconfigurando los escenarios mediáticos, al permitir el crecimiento de espacios alternativos o contrahegemónicos en los que la comunicación puede ocurrir de forma más horizontal o reticular, las continuas dinámicas de visibilización lo que están haciendo es generar espacios de disputa por la conquista de "testimonios mediáticos de existencia" (Rocha, 2009).

Este contexto exige, al mismo tiempo, diferenciar entre visualidad y visibilidad. La visualidad se refiere a la posibilidad de ser visto a través de imágenes. La visibilidad, en cambio, va mucho más allá. Esta está relacionada con las estructuras compartidas que otorgan, a determinadas imágenes, características y elementos que le dan relevancia social. La visibilidad, por tanto, conlleva legibilidad y legitimidad sociocultural. Lo visible se instituye por medio de embates sociales y estrategias comunicacionales; posee un valor de intercambio simbólico y de relevancia comunicativa y es un fragmento significante de un entorno visual mucho más amplio (Rocha, 2009).

A pesar de que vivimos en una sociedad donde las imágenes (visualidades) son omnipresentes, no todas ellas adquieren un status de visible (visibilidad). Los medios son, por excelencia, la instancia donde se dan los desplazamientos entre lo invisible y lo visible. Cogo (2007) expone que los medios confieren visibilidad a las acciones de sectores sociales e instituciones, asegurando su existencia y carácter estructural. Y, en esta coyuntura mediática, los movimientos sociales y las actividades de determinados agentes se van posicionando progresivamente sorteando las tensiones que genera la búsqueda de esa visibilidad pública, tensiones que les obliga a (re)componer sus lógicas y, a los medios, a transformarse en un espacio simbólico de conflictos y negociaciones. De esos continuos enfrentamientos, resultan las políticas de visibilidad. A través de esas micropolíticas cotidianas hacia la visibilidad, la inclusión de una multiplicidad de demandas simbólicas y materiales va entrando en la agenda política (Cogo, 2007). Siendo las visualidades y, consecuentemente, las visibilidades valoradas de manera asimétrica, las 
políticas de visibilidad se asocian íntimamente con las "políticas de representación" (García Canclini, 2000).

En particular, con relación a la temática de las migraciones, es importante destacar el impacto que la profusión de imágenes ha producido en las (de)construcciones de las representaciones mediáticas no solo en lo que a las migraciones en general se refiere, sino también sobre la persona que migra, su origen y destino, modelándose así un imaginario colectivo acerca del Otro-migrante. Para pensar acerca de esta cuestión, hay que tener en cuenta que el dominio de las visualidades en las sociedades contemporáneas también obedece a las lógicas del capital y de la globalización, lo que normalmente conduce a la espectacularización y al estereotipo. Y esto, a su vez, puede reducir la capacidad de transformación política de estos contenidos.

Un ejemplo evidente de esta potencial pérdida de fuerza política es lo sucedido con la fotografía de Aylan Kurdi, un niño sirio que murió ahogado en un intento de atravesar el mar Egeo hacia Grecia (Europa). La imagen del cuerpo de Aylan Kurdi en la orilla de una playa en Bodrum (Turquía) se hizo célebre en $2015^{4}$. Una imagen que Andrés, Nos Aldas y García Matilla (2016) califican como "transformadora", "de cambio social", por haber adquirido una clara dimensión política. La fotografía de Aylan Kurdi tuvo una gran repercusión mediática y acabó teniendo un carácter simbólico, convirtiéndose en un modo de mostrar la "crisis migratoria". "Los informativos de televisión facilitaron la secuencia completa en planos generales mucho más alejados de la víctima. (...) Sin embargo, esas imágenes no consiguieron el impacto emocional de la imagen fija" (Andrés, Nos Aldas y García Matilla, 2016, p. 32).

El problema que queremos destacar aquí no son los dilemas éticos que se derivan de la explotación de su efecto dramático e impacto emotivo o del hecho de que fuera la imagen de un niño, sino en cómo su excesiva reproducción consiguió llegar a vaciarla de contenido. Aunque tal y como apuntan Andrés, Nos Aldas y García Matilla (2016), la imagen planteó cierto giro en el enfoque discursivo del problema -reflejado, por ejemplo, en que el uso de la palabra "refugiado" llegó a superar al de "inmigrante" en las búsquedas en Google coincidiendo con su publicación-, la excesiva reproducción llevó a su agotamiento. Además de que esta imagen acabó ocultando otras muertes igual de trágicas al erigirse como icono, la imagen no causó finalmente grandes cambios en el discurso periodístico preexistente sobre las personas refugiadas (Bozdag y Smets, 2017).

Los regímenes de hipervisibilidad de inmigrantes y refugiados en los medios hegemónicos no asegura que estas persones puedan gestionar su visibilidad. Es decir, no garantiza que puedan hablar sobre sus experiencias $\mathrm{y}$, mucho menos, proponer modos de representación. Por contra, es recurrente la mediación de otros agentes sociales, como "especialistas" o instituciones. Justamente es aquí donde radica el problema de que no toda visualidad alcance a ser visibilidad, pues todo ello conlleva una elevada complejidad comunicativa, cargada de disputas y negociaciones de significados. No todas las 
voces son escuchadas; no todas las personas aparecen representadas mediáticamente. Así, resulta imprescindible problematizar sobre la visibilidad y la visualidad, dado que las imágenes, además de portadoras de sentido, contienen un carácter eminentemente político (Georgiou, 2018).

\section{DINÁMICAS DE (IN)VISIBILIDAD Y SUJETOS LGTBIQ+ MIGRANTES}

Una vez que se comprende que las relaciones sociales están, directa o indirectamente, mediadas por las imágenes, cabe preguntarse: "Entonces, ¿qué y a quién puede mostrarse?". En un tiempo de segmentaciones, heterogeneidad y comunicaciones transnacionales fluidas (García Canclini, 2000), se podría suponer que la invisibilidad no es un problema. Sobre todo, si, además, tenemos en cuenta el desarrollo de las TICs y la paralela expansión del lenguaje visual con la proliferación digital de imágenes y fotografías. Pero, por si sola, la técnica no garantiza la igualdad y, al mismo tiempo, la tecnología tampoco es neutra, basta con pensar en la discusión actual sobre los sesgos que provocan los algoritmos en las búsquedas en internet en el marco de la Inteligencia Artificial.

En el caso de las minorías sociales, la lucha por conseguir la visibilidad va ligada a la defensa de una imagen respetuosa, digna, no estereotipada. Pero, para abordar de forma específica las (in)visibilidades en relación con personas migrantes LGTBIQ+, antes es necesario comprender de qué modo las miradas heterocentradas han marcado la manera de experimentar nuestros cuerpos, deseos, identidades de género y orientaciones sexuales. De acuerdo con Judith Butler (2011), estas miradas vienen pautadas por el orden establecido a partir del eje sexo/género/sexualidad, derivado de un sistema binario, que ha perpetuado a lo largo del tiempo la creencia en una relación directa (natural) entre las tres instancias. Para rebatir este componente natural, basta con pensar en cómo los roles sociales derivados de la configuración sexo/género/sexualidad pueden dejar de ser lógicos cuando se trasladan a otros contextos culturales (Galofre y Missé, 2017).

Pero los géneros normativos van más allá de una vivencia personal e íntima como algunos creen. Las identidades de género deben ser comprendidas como formadas relacionalmente y, por tanto, se desarrollan en las interacciones sociales. Las personas LGTBIQ+ se asocian con comportamientos transgresores, disidentes, no convencionales, que rompen con la hegemonía de los ordenamientos binarios. Sobrepasar esas fronteras significa pasar a ser vulnerable a innumerables formas de violencias, simbólicas, físicas e, incluso, institucionalizadas, llegando a poder perder el status de "humano" (Butler, 2011). Por el contrario, cuanto mayor es la correspondencia con el patrón hegemónico normativo, más plausibles se vuelven los códigos de visibilidad que aseguran una legibilidad sociocultural. La disidencia de la divisa de normalidad representa la consiguiente subalternización, vulnerabilidad y precarización de la existencia, 
como ocurre con los sujetos LGTBIQ+ (Manalansan IV, 2006). Aunque, dentro del colectivo, también hay diferencias:

Dado que en esta cultura la ambigüedad de género y los géneros no normativos son invisibilizados, y que aquellos transgresores del género son sistemáticamente silenciados (y por ello invisibilizados), la violenta rigidez de las defensoras del género se dirige hacia aquellas etiquetas más familiares, más cercanas: la homosexualidad o el lesbianismo, aquellos puntos en los que los géneros no normativos se cruzan con los sexos no normativos (Bornstein, 2017, p. 120).

En cuanto a las experiencias migratorias de sujetos LGTBIQ+, siempre hay una desestabilización interseccional ${ }^{5}$ de lo normativo. Por un lado, como sucede en todos los desplazamientos humanos, se rompe con un pretendido ordenamiento geográfico basado en la distinción entre lo local, lo internacional y lo transnacional, cuyo cruce supone la transición por diferentes culturas (Bhabha, 2013) y, por otro, hay una desestabilización de los códigos productores de subjetividad fundamentados en una matriz heterocisnormativa (Wesling, 2008). Pero, además, en esta interseccionalidad aparecen otros marcadores sociales de diferencia, como pueden ser el origen étnico, la raza, la clase social, la edad o la religión.

En determinados países no hay garantías ciudadanas de respeto de derechos hacia los sujetos LGTBIQ+, a quienes se considera meros objetos de abuso y discriminación. Esta inseguridad incluye insultos, persecuciones, arrestos arbitrarios, torturas, violencia sexual y asesinatos (Manalansan IV, 2006). Por tanto, emigrar desde coyunturas socioculturales intensamente represivas no supone solo la posibilidad de disfrutar de una mayor libertad sino directamente poder sobrevivir (Wesling, 2008).

Los desplazamientos internos (dentro de los límites de un Estado-nación), como la migración desde áreas rurales a urbanas o desde pequeñas a grandes ciudades, fue -y sigue siendo- algo recurrente para sujetos cuyos deseos afectivo-sexuales y/o identidades de género no responden al régimen disciplinario heterocisnormativo (Andrade, 2017). Los grandes centros urbanos atraen a sujetos LGBITQ+, ya que estos son espacios que permiten una mayor libertad a la expresión de diferencias, una menor vigilancia social y un relativo anonimato (Nascimento, 2018). Evidentemente las violencias dirigidas a estas personas no dejan de ocurrir en ese contexto, pero, al mismo tiempo, los circuitos urbanos, quizá por dar más cabida al espacio público, propician el desarrollo de un sentimiento de comunidad y pertenencia.

En lo que se refiere a las migraciones inter o transnacionales, hay que atender a dos tipos de desplazamientos. El primero se refiere a las migraciones de carácter voluntario, que pueden responder a motivos muy diferentes: estudios, trabajo, vínculos familiares, factores culturales, etc. En esta categoría de movilidad humana, la persona no se siente rigurosamente obligada a abandonar su país de origen, pero la cuestión de la orientación 
sexual y/o identidad de género también puede estar presente, operando incluso como un principio decisivo en la migración.

El segundo se refiere a una categoría específica de desplazamiento humano que ha de responder a un status migratorio regulado: la solicitud de refugio. En 1951, en la Convención sobre el Estatuto de los Refugiados, se acordó caracterizar a la persona refugiada como aquella que "temiendo ser perseguida por motivos de raza, religión, nacionalidad, grupo social u opiniones políticas, se encuentra fuera del país de su nacionalidad y no puede o, en virtud de ese temor, no quiere valerse de la protección de ese país" (UN, 1951, p. 3). En el año 1967, con el Protocolo sobre el Estatuto de los Refugiados, estos criterios pasaron a estar vigentes de forma más amplia, en el marco del derecho internacional, para la aceptabilidad de las solicitudes de refugio.

Sin embargo, en ninguno de los dos documentos, ni la orientación sexual ni la identidad de género están explícitamente enumeradas como razones pertinentes para solicitar o conceder el refugio (Nascimento, 2018). No obstante, por la polisemia de la noción "grupo social", la condición de refugiado se expandió a otros perfiles no encuadrados en estos documentos, como es el caso de mujeres que sufren violencia de género en su país de origen y, posteriormente, los sujetos LGTBIQ+. La primera aprobación de una solicitud de un miembro del colectivo LGTBIQ+ ocurrió en Holanda, en la década de 1980 (Nascimento, 2018) y, en la actualidad, algunos países ya consideran la intolerancia, los prejuicios y las violencias con que son tratadas cotidianamente las personas LGTBIQ+ como motivos válidos para justificar una solicitud de refugio.

Ahora bien, no existiendo una especificación legal que asegure la protección integral de las personas refugiadas $\mathrm{LGTBIQ+}$, la aceptación de la solicitud de refugio y su concesión acaba dependiendo de algo tan subjetivo como es el parecer del cuerpo jurídico del Estado-nación de destino. Según indica Nascimento (2018), en los Estados Unidos, por ejemplo, a veces es necesario comprobar que el solicitante LGTBIQ+ de refugio realmente lo es, pero ¿cómo una persona puede mostrar su identidad de género u orientación sexual? No basta con ser LGTBIQ +, tiene que parecerlo. Es decir, se trata de exagerar características de legibilidad no heteronormativa, lo que lleva inexorablemente a mostrar una imagen estereotipada, a aplicar códigos preconcebidos y formateados de acuerdo con el reverso del patrón de la "normalidad".

En definitiva, como puede deducirse de lo expresado hasta aquí, la solicitud de refugio es un proceso extremadamente complejo y la resolución positiva está subordinada a aprobaciones institucionales en el país de destino. La persona LGTBIQ+ vive irremediablemente el temor de la persecución, por no citar otros sentimientos que pueden darse en la fase de comprobación de su orientación sexual y/o identidad de género que, en muchos casos, es visual (Nascimento, 2018). 
Todo lo dicho hasta aquí ayuda a entender por qué las (in)visibilidades mediáticas en las experiencias migratorias de sujetos LGTBIQ+ son altamente relevantes. Luchar por una mayor visibilidad implica resistirse, actuar y ejercer la ciudadanía. No es casual que visibilidad y activismo hayan ido de la mano en la historia social de este colectivo y, si a ello se suma la cuestión del refugio, el problema es aún mayor.

Además, aparece aquí también la paradoja del deseo de la asimilación, del pasar desapercibido. Por un lado, hay la necesidad de visibilizarse en el espacio público y, para ello, se entablan luchas por el reconocimiento, por la obtención de derechos y por las transformaciones socioculturales en el entorno. Por otro lado, esa visibilización incrementa la vulnerabilidad. Una vez anclado en la visibilidad, de algún modo se acaban reafirmando las diferencias de carácter ontológico que sostienen precisamente las desigualdades impuestas desde una cultura heteronormativa.

Las personas inmigrantes y refugiadas $L G T B I Q+$ pueden ocultar su orientación sexual y/o identidad de género para evitar comportamientos discriminatorios en la sociedad de destino, pero, al mismo tiempo, también es muy común ocultarlo entre las personas compatriotas con las que conviven, pues en estos círculos también se pueden reproducir las discriminaciones de las sociedades de origen (Andrade, 2017). Además, mucho sabemos ya del comportamiento vigilante entre los miembros de familias transnacionales gracias a estudios feministas sobre el control que hombres ejercen sobre mujeres en el marco de parejas sentimentales heterosexuales. $Y$, a todo ello, se puede agregar la experiencia de la clandestinidad (intrínseca a las migraciones), pues la falta de una regularización jurídica conlleva la obligación de tener cautela a ser visto en los espacios públicos.

Al lado de estas dinámicas aparecen los medios de comunicación, generando y expandido sentidos y narrativas sobre las experiencias y vivencias de estas personas. En un estudio anterior sobre la representación mediática de personas refugiadas LGTBIQ+ en contenidos de portales digitales de noticias brasileñas, fue posible verificar, por ejemplo, una tendencia a la reproducción de estereotipos, que limitaba el entendimiento de las complejas relaciones sociales, culturales, históricas y políticas que se engloban en las experiencias migratorias de esos sujetos, debilitando, por consiguiente, la aprehensión de sus singularidades (Theodoro, 2017). Es decir, las negociaciones y los conflictos de la población migrante LGTBIQ+ aparecen registradas en los medios, y estas acaban impactando directamente en su visibilidad mediática.

\section{EL TRATAMIENTO PERIODISTICO DE LA PRIDE BCN 2018}

\subsection{Apuntes metodológicos}

Durante el mes de febrero de 2019, se realizó una búsqueda del material publicado sobre la Pride BCN 2018, cuyo lema fue: "Por los refugiados LGTBI", en la versión online 
de tres diarios españoles, El País, El Mundo y La Vanguardia. Los tres diarios son de referencia en España, aunque según los datos de la AIMC de principios de 2019, solo tienen posiciones destacadas en el ranking de consumo digital El País y La Vanguardia. Utilizamos como herramienta de búsqueda el sitio web de los propios diarios digitales, además de Google.com. En total, se encontraron 17 noticias sobre la Pride BCN 2018: 2 (El Mundo), 6 (El País) y 9 (La Vanguardia). Dado el reducido volumen de material hallado, optamos por formar el corpus de análisis con todos los textos.

Clasificamos la temática tratada en cada pieza a partir de la siguiente tipología:

a) Divulgación del evento: información sobre las actividades incluidas en la Pride BCN (conciertos, fiestas, desfiles, exposiciones, charlas, etc.).

b) Refugio de sujetos LGTBIQ+: Información específica sobre algún aspecto relacionado con $L G T B I Q+$ y refugio.

c) Otro: Noticias donde el foco de atención es otro.

\subsection{Ausencia de la temática del refugio de sujetos LGTBIQ+}

El $64,7 \%$ de las noticias analizadas (11) no discuten de manera directa sobre la temática de reivindicación y visibilidad del evento ("Por los refugiados LGTBI"). Como podemos observar en la Tabla 1, las dos noticias publicadas en El Mundo no están directamente relacionadas con la Pride BCN 2018 y tampoco tratan la cuestión del refugio de personas LGTBIQ+. Esto también sucede con una de las noticias aparecidas en La Vanguardia, que habla sobre una infección por salmonela durante el evento. Y, por último, otras 8 noticias ( 3 de El País y 5 de La Vanguardia) tratan exclusivamente de las actividades realizadas durante el evento.

Por tanto, los resultados obtenidos corroboran la tendencia apuntada en el marco teórico que señala hacia la supresión, o invisibilidad mediática, de la experiencia migratoria de los sujetos LGTBIQ+ refugiados. Además, el hecho de destacar la divulgación de la Pride BCN 2018 también puede vincularse a un mayor interés por su uso como reclamo comercial y turístico, sobre todo si tenemos en cuenta la relación institucional que se ha establecido entre Barcelona y el colectivo LBGTIQ+ y los importantes aportes económicos que ello ha generado (Forga, 2015). En este sentido, es importante recordar que la Pride BCN nació como una iniciativa de la Asociación Catalana de Empresas para Gays y Lesbianas (ACEGAL). 
Tabla 1

Corpus de análisis: información básica

\begin{tabular}{|c|c|c|c|c|}
\hline $\begin{array}{l}\text { Diario } \\
\text { on line }\end{array}$ & Título de la materia & $\begin{array}{l}\text { Fecha de } \\
\text { publicación }\end{array}$ & $\begin{array}{l}\text { Contenidos } \\
\text { abordados }\end{array}$ & $\begin{array}{c}\text { Enlace de acceso } \\
\text { (disponible el } 6 \text { mayo de 2019) }\end{array}$ \\
\hline \multirow{2}{*}{$\begin{array}{c}\text { El } \\
\text { Mundo }\end{array}$} & $\begin{array}{l}\text { La Crida LGTBI de- } \\
\text { nuncia el "lavado rosa" } \\
\text { de imagen de empre- } \\
\text { sas a través del Pride }\end{array}$ & $26 / 06 / 2018$ & Otro & $\begin{array}{l}\text { https://www.elmundo.es/cata- } \\
\text { luna/2018/06/26/5b326d1fe5fdea9e288b45a2.html }\end{array}$ \\
\hline & $\begin{array}{c}\text { Colau cuelga la ban- } \\
\text { dera arco iris en la fa- } \\
\text { chada del Ayunta- } \\
\text { miento }\end{array}$ & $28 / 06 / 2018$ & Otro & \begin{tabular}{|l} 
https://www.elmundo.es/cata- \\
luna/2018/06/28/5b34f72d268e3e017a8b457d.html
\end{tabular} \\
\hline \multirow{6}{*}{ El País } & $\begin{array}{l}\text { El ‘Orgullo' de Barce- } \\
\text { lona se vuelca con los } \\
\text { refugiados LGTBI }\end{array}$ & $03 / 05 / 2018$ & $\begin{array}{l}\text { Divulgación } \\
\text { del evento }\end{array}$ & $\begin{array}{l}\text { https://elpais.com/ccaa/2018/06/30/cata- } \\
\text { lunya/1530385170_792738.html }\end{array}$ \\
\hline & $\begin{array}{l}\text { El Orgullo de Barce- } \\
\text { lona volverá a cele- } \\
\text { brarse en la Avenida } \\
\text { María Cristina }\end{array}$ & $25 / 06 / 2018$ & $\begin{array}{c}\text { Divulgación } \\
\text { del evento; } \\
\text { Refugio de } \\
\text { sujetos } \\
\text { LGTBIQ+ }\end{array}$ & $\begin{array}{l}\text { https://elpais.com/ccaa/2018/05/03/cata- } \\
\text { lunya/1525374084_279979.html }\end{array}$ \\
\hline & $\begin{array}{l}\text { Art i suport als refu- } \\
\text { giats a l'Orgull Gai de } \\
\text { Barcelona }\end{array}$ & $29 / 06 / 2018$ & $\begin{array}{c}\text { Divulgación } \\
\text { del evento; } \\
\text { Refugio de } \\
\text { sujetos } \\
\text { LGTBIQ+ } \\
\end{array}$ & $\begin{array}{l}\text { https://cat.elpais.com/cat/2018/06/25/cata- } \\
\text { lunya/1529918922_115590.html }\end{array}$ \\
\hline & $\begin{array}{l}\text { L'Orgull de Barcelona } \\
\text { es bolca amb els refu- } \\
\text { giats LGTBI }\end{array}$ & $30 / 06 / 2018$ & $\begin{array}{c}\text { Divulgación } \\
\text { del evento; } \\
\text { Refugio de } \\
\text { sujetos } \\
\text { LGTBIQ+ }\end{array}$ & $\begin{array}{l}\text { https://cat.elpais.com/cat/2018/06/30/cata- } \\
\text { lunya/1530385170_792738.html }\end{array}$ \\
\hline & $\begin{array}{l}\text { Barcelona es mani- } \\
\text { festa aquest dissabte } \\
\text { per les persones refu- } \\
\text { giades LGTBI }\end{array}$ & $30 / 06 / 2018$ & $\begin{array}{l}\text { Divulgación } \\
\text { del evento }\end{array}$ & $\begin{array}{l}\text { https://cat.elpais.com/cat/2018/06/29/cata- } \\
\text { lunya/1530285833_263933.html }\end{array}$ \\
\hline & $\begin{array}{l}\text { L'Orgull gai omple } \\
\text { Barcelona de con- } \\
\text { certs, festes i activitats }\end{array}$ & 01/07/2018 & $\begin{array}{l}\text { Divulgación } \\
\text { del evento }\end{array}$ & $\begin{array}{l}\text { https://cat.elpais.com/cat/2018/06/29/cata- } \\
\text { lunya/1530274031_171375.html }\end{array}$ \\
\hline \multirow{4}{*}{$\begin{array}{l}\text { La Van- } \\
\text { guardia }\end{array}$} & $\begin{array}{l}\text { Los actos más desta- } \\
\text { cados de la fiesta del } \\
\text { Orgullo Gay }\end{array}$ & 03/05/2018 & $\begin{array}{c}\text { Divulgación } \\
\text { del evento; } \\
\text { Refugio de } \\
\text { sujetos } \\
\text { LGTBIQ+ } \\
\end{array}$ & $\begin{array}{c}\text { https://www.lavanguardia.com/local/barce- } \\
\text { lona/20180628/45395710526/pride-barcelona- } \\
\text { guia-fiesta-orgullo-gay-2018.html }\end{array}$ \\
\hline & $\begin{array}{l}\text { Conchita Wurst y Lo- } \\
\text { reen, hoy en el Pride } \\
\text { Barcelona } 2018\end{array}$ & $28 / 06 / 2018$ & $\begin{array}{l}\text { Divulgación } \\
\text { del evento }\end{array}$ & $\begin{array}{l}\text { https://www.lavanguardia.com/cul- } \\
\text { tura/20180629/45477661810/orgullo-gay-lgtbi-bar- } \\
\text { celona-pridegay-2018.html }\end{array}$ \\
\hline & $\begin{array}{l}\text { Los refugiados LGTBI } \\
\text { centran el Pride Bar- } \\
\text { celona } 2018\end{array}$ & 29/06/2018 & $\begin{array}{l}\text { Divulgación } \\
\text { del evento }\end{array}$ & $\begin{array}{l}\text { https://www.lavanguar- } \\
\text { dia.com/vida/20180630/45519806421/pride-barce- } \\
\text { lona-dia-orgullo-gay.html }\end{array}$ \\
\hline & $\begin{array}{c}\text { Pride Barcelona } 2018 \\
\text { logra récord histórico } \\
\text { con más de } 380.000 \\
\text { asistentes }\end{array}$ & $29 / 06 / 2018$ & $\begin{array}{c}\text { Divulgación } \\
\text { del evento; } \\
\text { Refugio de } \\
\text { sujetos } \\
\text { LGTBIQ+ }\end{array}$ & $\begin{array}{c}\text { https://www.lavanguar- } \\
\text { dia.com/vida/20180703/45612772290/pride-barce- } \\
\text { lona-2018-logra-record-historico-con-mas-de- } \\
\text { 380000-asistentes.html }\end{array}$ \\
\hline
\end{tabular}


Tabla 1 (Continuación)

\begin{tabular}{|c|c|c|c|c|}
\hline $\begin{array}{l}\text { Diario } \\
\text { on line }\end{array}$ & Título de la materia & $\begin{array}{l}\text { Fecha de } \\
\text { publicación }\end{array}$ & $\begin{array}{l}\text { Contenidos } \\
\text { abordados }\end{array}$ & $\begin{array}{c}\text { Enlace de acceso } \\
\text { (disponible el } 6 \text { mayo de 2019) }\end{array}$ \\
\hline & $\begin{array}{l}\text { Se eleva a } 29 \text { los afec- } \\
\text { tados por un brote de } \\
\text { salmonela en el Pride } \\
\text { Barcelona }\end{array}$ & $30 / 06 / 2018$ & Otro & $\begin{array}{c}\text { https://www.lavanguardia.com/local/barce- } \\
\text { lona/20180710/45794714017/brote-salmonela- } \\
\text { pride-barcelona-2018.html }\end{array}$ \\
\hline & $\begin{array}{l}\text { El Pride Barcelona } \\
\text { reivindicará los dere- } \\
\text { chos de las personas } \\
\text { refugiadas LGTBI }\end{array}$ & $30 / 06 / 2018$ & $\begin{array}{c}\text { Divulgación } \\
\text { del evento; } \\
\text { Refugio de } \\
\text { sujetos } \\
\text { LGTBIQ+ }\end{array}$ & $\begin{array}{c}\text { https://www.lavanguardia.com/local/barce- } \\
\text { lona/20180503/443206919064/pride-barcelona- } \\
\text { 2018-reivindicara-derechos-personas-refugiadas- } \\
\text { lgtbi.html }\end{array}$ \\
\hline & $\begin{array}{l}\text { El Pride esclata nova- } \\
\text { ment a Barcelona amb } \\
\text { la mirada posada en } \\
\text { els refugiats LGTBi }\end{array}$ & $30 / 06 / 2018$ & $\begin{array}{l}\text { Divulgación } \\
\text { del evento }\end{array}$ & $\begin{array}{c}\text { https://www.lavanguardia.com/local/barcelones- } \\
\text { nord/20180630/45524719490/el-pride-esclata-no- } \\
\text { vament-a-barcelona-amb-la-mirada-posada-en-els- } \\
\text { refugiats-lgtbi.html }\end{array}$ \\
\hline & $\begin{array}{c}\text { Todos los conciertos } \\
\text { del Pride Barcelona } \\
2018\end{array}$ & 03/07/2018 & $\begin{array}{l}\text { Divulgación } \\
\text { del evento }\end{array}$ & $\begin{array}{c}\text { https://www.lavanguardia.com/cul- } \\
\text { tura/20180629/45467763448/conciertos-pride-bar- } \\
\text { celona-orgullo-2018.html }\end{array}$ \\
\hline & $\begin{array}{l}\text { Las mejores imágenes } \\
\text { de un Día del Orgullo } \\
\text { cada vez más consoli- } \\
\text { dado en el calendario }\end{array}$ & $10 / 07 / 2018$ & $\begin{array}{l}\text { Divulgación } \\
\text { del evento }\end{array}$ & $\begin{array}{l}\text { https://www.lavanguar- } \\
\text { dia.com/vida/20180630/45519125980/orgullo-gay- } \\
\text { pride-manifestacion-espana.html }\end{array}$ \\
\hline
\end{tabular}

Fuente: elaboración propia

\subsection{Ausencia del colectivo de refugiados LGTBIQ+}

Como es posible comprobar en la Tabla 2, la voz de los sujetos LGTBIQ+ refugiados tan solo se da en una de las noticias ("El Orgullo de Barcelona volverá a celebrarse en la Avenida María Cristina", publicada en El País). Por el contrario, las declaraciones de uno de los organizadores del evento aparecen en tres noticias.

Y, además, el único texto que incluye la voz del refugiado LGTBIQ+ apenas aporta alguna información sobre sus experiencias de vida. La voz del sujeto refugiado LGTBIQ+ no ha sido considerada como fuente solvente, mediadora eficaz, y ha pasado a ser absorbida por un complejo proceso simbólico como es la Pride, capaz de desestabilizar el reconocimiento de los sujetos LGTBIQ+ refugiados a partir del fortalecimiento del estereotipo (la cultura gay asociada a la fiesta, la diversión y el ocio). 
Tabla 2

Enfoque sobre el colectivo de sujetos refugios $L G T B I Q+$ en el corpus analizado

\begin{tabular}{|c|c|c|}
\hline $\begin{array}{l}\text { Diario on } \\
\text { line }\end{array}$ & Título de la materia & $\begin{array}{c}\text { Extracto referente al refugio } \\
\text { de sujetos } L G T B I Q+\end{array}$ \\
\hline \multirow{3}{*}{ El País } & $\begin{array}{l}\text { El Orgullo de Barcelona } \\
\text { volverá a celebrarse en la } \\
\text { Avenida María Cristina }\end{array}$ & $\begin{array}{l}\text { "Carol, la mujer que da la cara en el cartel principal, y testimonio de la } \\
\text { campaña de Refugiados LGTBI, ha expresado que en Barcelona } \\
\text { siente que su vida ya no corre peligro: 'Como persona me he vuelto a } \\
\text { reconstruir, ahora estoy más segura de mí misma y tengo esperanza. } \\
\text { Por eso el apoyo de la gente de aquí es muy importante', y ha con- } \\
\text { tado que llegó a la ciudad hace un año y medio". }\end{array}$ \\
\hline & $\begin{array}{l}\text { Art i suport als refugiats a } \\
\text { l'Orgull Gai de Barcelona }\end{array}$ & $\begin{array}{l}\text { "Ser homosexual o transsexual està perseguit en més de } 80 \text { països } \\
\text { del món. L'associació ACATHI, formada per migrants, refugiats i per- } \\
\text { sones LGTBI organitza aquest dimecres } 27 \text { de juny una conferència } \\
\text { per visibilitzar algunes iniciatives i experiències destinades a atendre } \\
\text { les persones d'aquest col·lectiu que demanen asil a Espanya. EI } \\
2017 \text {, ACATHI, va atendre } 200 \text { persones a nivell legal, psicològic i as- } \\
\text { sistencial, amb l'oferiment de places de pisos. Aquest any, el seu pre- } \\
\text { sident, Rodrigo Araneda, preveu que la xifra es duplicarà fins els } 400 \\
\text { casos. Moltes d'aquestes persones provenen del Marroc, Rússia, Ve- } \\
\text { neçuela i Hondures". }\end{array}$ \\
\hline & $\begin{array}{l}\text { L'Orgull de Barcelona es } \\
\text { bolca amb els refugiats } \\
\qquad \text { LGTBI }\end{array}$ & $\begin{array}{l}\text { "Aquest any, l'Orgull va posar el focus en la greu situació que viuen } \\
\text { els refugiats LGTBI. L'organització va recordar que en més de } 80 \\
\text { països del món, pertànyer a aquest col·lectiu implica "persecució, tor- } \\
\text { tura, presó i fins i tot intents d'assassinat". }\end{array}$ \\
\hline \multirow{3}{*}{$\begin{array}{l}\text { La Van- } \\
\text { guardia }\end{array}$} & $\begin{array}{l}\text { Los actos más destaca- } \\
\text { dos de la fiesta del Orgu- } \\
\text { llo Gay }\end{array}$ & $\begin{array}{l}\text { "'Este es uno de los Pride más importantes a nivel social porque } \\
\text { siempre queremos reivindicar una temática, que ahora serán las per- } \\
\text { sonas refugiadas LGTBI', ha asegurado el director del festival, Eloi } \\
\text { Morte, que ha lamentado que 'si ser una persona refugiada es com- } \\
\text { plicado, si además eres LGTBI lo es todavía más'. } \\
\text { La campaña, cuyo objetivo es 'concienciar a toda la ciudadanía sobre } \\
\text { las posibilidades de colaborar en su adaptación y ayudarles a empe- } \\
\text { zar una nueva vida', está compuesta por carteles con microhistorias } \\
\text { de personas que han tenido que huir de sus países por su orientación } \\
\text { sexual". }\end{array}$ \\
\hline & $\begin{array}{l}\text { Pride Barcelona } 2018 \text { lo- } \\
\text { gra récord histórico con } \\
\text { más de } 380.000 \text { asisten- } \\
\text { tes }\end{array}$ & $\begin{array}{l}\text { "Hemos cumplido nuestros objetivos: dar voz y visibilizar a las perso- } \\
\text { nas refugiadas LGTBI que se ven obligadas a huir de sus países de } \\
\text { origen por su orientación sexual y necesitan nuestro apoyo, además } \\
\text { de recuperar el orgullo por esta celebración en Barcelona en la propia } \\
\text { ciudadanía", ha explicado el director del evento, Eloi Morte. }\end{array}$ \\
\hline & $\begin{array}{l}\text { El Pride Barcelona reivin- } \\
\text { dicará los derechos de las } \\
\text { personas refugiadas } \\
\text { LGTBI }\end{array}$ & $\begin{array}{l}\text { "'Éste es uno de los Pride más importantes a nivel social porque } \\
\text { siempre queremos reivindicar una temática, que ahora serán las per- } \\
\text { sonas refugiadas LGTBI', ha detallado el director del festival, Eloi } \\
\text { Morte, que ha lamentado que 'si ser una persona refugiada es com- } \\
\text { plicado, si además eres LGTBI lo es todavía más'. } \\
\text { La campaña para este colectivo está compuesta por carteles que ex- } \\
\text { ponen historias basadas en testimonios reales de personas que han } \\
\text { tenido que huir de Marruecos, Guatemala o Rusia por su orientación } \\
\text { sexual y que se han refugiado en Barcelona. } \\
\text { El objetivo es 'concienciar a toda la ciudadanía sobre las posibilida- } \\
\text { des de colaborar en su adaptación y ayudarles a empezar una nueva } \\
\text { vida en una ciudad tan diversa y abierta como Barcelona', una acción } \\
\text { que según Morte se podrá hacer a través de donaciones, recogida de } \\
\text { alimentos o apoyo social". }\end{array}$ \\
\hline
\end{tabular}

Fuente: elaboración propia 
Se evidencia, una vez más, la falta de espacio mediático para el agenciamiento y participación de los sujetos refugiados LGTBIQ+. La representación mediática detectada en nuestro análisis reproduce el cuadro de silenciamiento e invisibilidad a que los sujetos LGTBIQ+ refugiados son proclives. Lo que se visibiliza aquí no es a los sujetos y sus experiencias migratorias, sino el propio evento.

Por tanto, continúa siendo necesario cuestionar el orden comunicacional que permite que sólo algunas voces puedan hablar (y ser escuchadas) y que la mayoría sean suprimidas (Georgiou, 2018). Sobre todo, si cuando analizamos material periodístico sobre un evento protagonizado y dirigido al colectivo, ello no acaba repercutiendo positivamente en su representación mediática. Continúa siendo necesario defender el derecho a tener habla en los medios y a la construcción de vías de comunicación más dialógicas y horizontales en las representaciones mediáticas (Georgiou, 2018), para poder adoptar una agencia reflexiva de y para estos sujetos: una verdadera base para la creación de narrativas de sí mismos, capaces de generar, o incluso convertirse, en políticas de diferencia.

\section{CONSIDERACIONES FINALES}

A partir de este estudio de caso sobre las representaciones mediáticas de sujetos refugiados $L G T B I Q+$, evidenciamos que las singularidades de sus experiencias migratorias no fueron centrales en el abordaje periodístico de la Pride BCN 2018, a pesar de que el lema del evento se focalizaba precisamente en ese asunto. Eso demuestra que, en las dinámicas de (in)visibilidad, estos discursos favorecen una presencia precaria. Siguiendo a Georgiou (2018), entendemos que el silenciamiento es también una forma de poder, de subordinación y de subalternización del sujeto, que, al mismo tiempo, deteriora su agencia política.

Cabe mencionar, además, que las representaciones mediáticas que se centran en los traumas y la victimización no hacen otra cosa que ratificar y legitimar las decisiones que se toman sobre ellos en los órganos de poder, al mostrarse como incapaces o desprovistos de capacidad de agencia. Así, tales discursos apoyan la idea de que estos sujetos son solamente cuerpos que requieren una gestión biopolítica. La perspectiva dada a la temática del refugio LGTBIQ+ (aunque no, sobre los sujetos refugiados) por El País y La Vanguardia camina en esa dirección.

Las fronteras simbólicas, en cuya delimitación los medios toman parte, constituyen prácticas representacionales de exclusión, que mantienen a los sujetos migrantes y refugiados fuera de los espacios de representación y deliberación. Y, como el poder que estos ejercen en calidad de mediadores es cada vez mayor, esto nos lleva a cuestionar las relaciones de fuerza que se dan entre los intereses de los medios y la lucha de los sujetos LGTBIQ+ por lograr una mayor visibilidad - poder hablar y poder ser escuchados-. Se trata de un verdadero campo de batalla por la visibilidad, la voz y el 
reconocimiento, que deja en evidencia la complejidad de esas "negociaciones" comunicacionales.

\section{Notas}

1 Cisgeneridad se refiere a la identificación automática del género a partir de los órganos genitales en el momento del nacimiento del individuo, fruto de los códigos socioculturales dominantes.

2 El estudio está vinculado a una investigación de doctorado actualmente en desarrollo, que busca analizar la (in)visibilidad sociocomunicacional de inmigrantes y refugiadas/os LGTBIQ+ en la ciudad brasileña de São Paulo. Entre noviembre de 2018 y octubre de 2019, a partir de una Estancia de Investigación en el Exterior (en el Institut de la Comunicació de la Universitat Autònoma de Barcelona, InCom-UAB), se busca ampliar el alcance del trabajo empírico a Barcelona, estableciendo un estudio comparativo entre dos contextos socioculturales. El estudio es financiado por la Fundación de Amparo a la Investigación del Estado de São Paulo (procesos 2016/24566-1 y 2018/18712-0).

${ }^{3}$ La Pride BCN es un evento que ocurre desde el año de 2008 en la ciudad de Barcelona durante el mes de junio. Según se indica en la web que la propia organización dispone, su objetivo es la celebración del orgullo LGTBI, siendo "un acontecimiento de carácter tanto reivindicativo como festivo, reforzando el compromiso de Barcelona con la lucha por los derechos y las libertades del colectivo LGTBI". Disponible en: https://www.pridebarcelona.org/. Último acceso: mayo de 2019.

${ }^{4}$ Recuperado el 1 de mayo de 2019:

https://www.elperiodico.com/es/internacional/20180902/aylan-tercer-ano-de-su-muerte7014362?utm_source=facebook\&utm_medium=social\&utm_campaign =cm

${ }^{5}$ Interseccionalidad corresponde a formas de aprehender los efectos de la interacción entre dos o más formas de precariedad: xenofobia, racismo, sexismo, misoginia, homofobia, lesbofobia, transfobia, etc. (Crenshaw, 1995).

\section{Referencias}

Andrade, V. L. (2017). Imigração e sexualidade: solicitantes de refúgio, refugiados e refugiadas por motivos de orientação sexual na cidade de São Paulo. 238 f. [Dissertação] Programa de Pós-Graduação em Antropologia Social da Universidade Federal de Santa Catarina.

Andrés, S.; Nos-Aldás, E. \& García-Matilla, A. (2016). La imagen transformadora. El poder de cambio social de una fotografía: la muerte de Aylan. Comunicar, XXIV(47), 29-37. DOI: http://dx.doi.org/10.3916/C47-2016-03

Arendt, H. (2007). A condição humana. Rio de Janeiro: Forense Universitária.

Bhabha, H. K. (2013). Nuevas minorías, nuevos derechos. Notas sobre cosmopolitanismos vernáculos. Buenos Aires: Siglo XXI Editores.

Bozdag, C. \& Smets, K. (2017). Understanding the Images of Alan Kurdi With "Small Data": A Qualitative, Comparative Analysis of Tweets About Refugees in Turkey and Flanders 
(Belgium). International Journal of Communication, 11, 4046-4069.

Bornstein, K. (2017). Terror de género, rabia de género. En P. Galofre y M. Misse, (Eds.), Políticas trans. Una antología de textos desde los estudios trans norteamericanos (pp. 117-134). Barcelna: Editorial EGALES.

Butler, J. (2011). Gender trouble: feminism and the subversion of identity. London: Routledge.

Cogo, D. (2007). Migrações contemporâneas como movimentos sociais: uma análise desde as mídias como instâncias de emergência da cidadania dos migrantes. Revista Fronteiras estudos midiáticos, IX(1), 64-73.

Charadeau, P. (2009). El discurso de la informacion: la construccion del espejo social. Barcelona: Gedisa.

Crenshaw, K. (1995). Mapping the margins: Intersectionality, identity, politics and violence against women of color. En K. Crenshaw, N. Cotanda, C. Peller \& K. Thomas (Eds.), Critical race theory. The key writings that formed the movement (pp. 357-383). Nueva York: The New Press.

Femenías, M. L. (2007). El género del multiculturalismo. Bernal: Universidad de Quilmas.

Forga, J. M. (2015). Las motivaciones de los turistas LGBT en la elección de la ciudad de Barcelona. Documents d'Anàlisi Geogràfica, 61(3), 601-621. DOI: https://doi.org/10.5565/rev/dag.314

Galofre, P. \& Misse, M. (Eds.) (2017). Políticas trans. Una antología de textos desde los estudios trans norteamericanos. Barcelna: Editorial EGALES.

Garcia Canclini, N. (2000). La globalización imaginada. Barcelona: Ediciones Paidos Iberica.

Geourgiou, M. (2018). Does the subaltern speak? Migrant voices in digital Europe. Popular Communication, 16(1), 45-57.

Gregorio, C. (1998). Migración femenina. Su impacto en las relaciones de género. Madrid: Narcea.

Huertas, A. (2018). El estudio de las minorías como audiencia. El caso de la población migrante. Anuario Electrónico de Estudios en Comunicación Social "Disertaciones", 11(1), 40-55. DOI: http://dx.doi.org/10.12804/revistas.urosario.edu.co/disertaciones/a.6276

Huertas, A. \& Luna, M. (2017). Religión y consumo mediático de las mujeres musulmanas del norte de África con experiencia migratoria. Revista Prisma Social. 2, 83-103.

Krzeslo, E. (2007). Migrations et parcours d'exil: les femmes s'imposent. REMHU - Revista Interdisciplinar da Mobilidade Humana, XV(29), 121-137.

Manalansan IV, M. (2006). Queer intersections: sexuality and gender in migration studies. The International Migration Review, 40(1), 224-249. 
Mezzadra, S. (2005). Derecho de fuga: migraciones, ciudadanía y globalización. Madrid: Traficantes de Sueños.

Nascimento, D. B. (2018). Refúgio LGBTI: panorama nacional e internacional. Porto Alegre: Editora Fi.

Rocha, R. M. (2009). É a partir de imagens que falamos de consumo: reflexões sobre fluxos visuais e comunicação midiática. En G. Castro y M. A. Baccega (Eds.), Comunicação e consumo nas culturas locais e global (pp. 268-293). São Paulo: ESPM.

Silverstone, R. (2010). La moral de los medios de comunicación - sobre el nacimiento de la polis de los medios. Buenos Aires: Amorrortu.

Theodoro, H. (2017). "Meu país em mim": discursos sobre imigração por orientação sexual na mídia brasileira. Comunicologia, 10(2), 164-181.

UN - United Nations High Commissioner for Refugees (UNHCR). (1951). Convention and protocol relating to the status of refugees, The UN Refugee Agency. Recuperado de https://www.unhcr.org/3b66c2aa10

Wesling, M. (2008). Why queer diaspora? Feminist Review, 90(1), 30-47. 


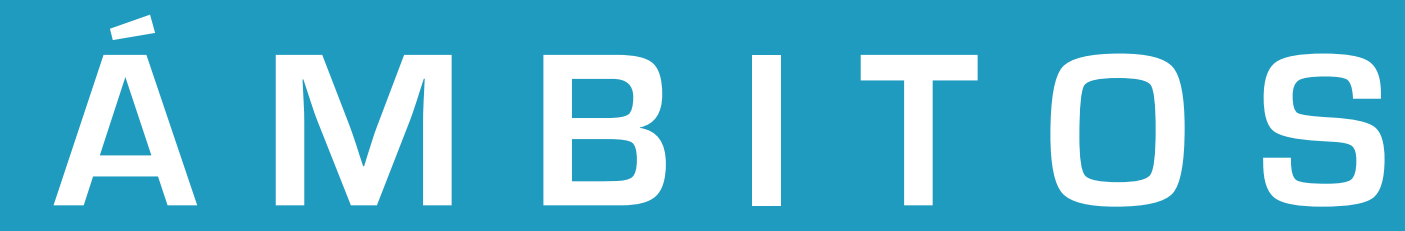

ISSN: 1139-1979 | ISSN digital: 1988-5733 | Depósito Legal: SE-1493-98

Revista Internacional de Comunicación editada por el Grupo de Investigación en Estructura, Historia y Contenidos de la Comunicación(GREHCCO) de la Universidad de Sevilla.

\section{ambitoscomunicacion@us.es}

http://institucional.us.es/ambitos

@RevistaAmbitos 